\title{
Dr Nils Rosen (1706-1773): the father of paediatrics in Sweden
}

\author{
P M Dunn
}

Nils Rosen was born in 1706, his father being a chaplain in the army of Charles XII. $\Lambda \mathrm{fter}$ schooling in Gothenburg, he studied medicine at the University of Lund from 1722-4 before taking up a tutorship in Stockholm. In 1727 he was appointed Adjunct by the University of Uppsala but spent the next three years travelling and studying on the continent, first in Germany and Switzerland, and then in Holland where he came under the influence of $\mathrm{Dr}$ Boerhaave of Leiden. He obtained an MD at the University of Harderwijk before returning to take up his teaching post in Uppsala in 1731. Nine years later he succeeded to the Chair of Medicine, becoming responsible for anatomy, physiology, pathology, therapeutics, chemistry and for directing the University Hospital. A second chair in theoretic and practical medicine was filled in 1741 by Carl Linné who became responsible for botany, materia medica, dietetics and semiotics, and Director of the Botanical Gardens.

Rosen was an excellent clinical teacher with a gift for simplifying complicated subjects. He pioneered the teaching of applied anatomy and bedside instruction in Sweden and did a great deal to promote child health and to introduce a better understanding of the needs of children among physicians and mothers.

He was a good correspondent but did not publish a great deal. His major work The Diseases of Children and their Remedies was first published in Sweden in 1764 and was later translated and published in English in $1776 .{ }^{1}$ It is from this work that the extracts that follow were taken. His book abounds with excellent advice on how to choose a good nurse, on breast feeding, on the dangers of overtight swaddling, and on other aspects of infant management. This, for example, was his advice on when to wet nurse an infant:

'The business of a nurse is to suckle the child whenever it is hungry or dry, but not by any means so often as it shrieks or cries . . . she may easily perceive when it wants to be suckled: (1) From the time it has gone without suck. (2) If it fixes its eyes on the nurse, and they seem as it were to follow her wherever she goes. (3) If joy sparkles from the child's eyes, when she opens her breasts. (4) By the child sucking her finger on its being put into its mouth'.

His chapter on thrush, a condition which was very prevalent at that time, is also of interest:

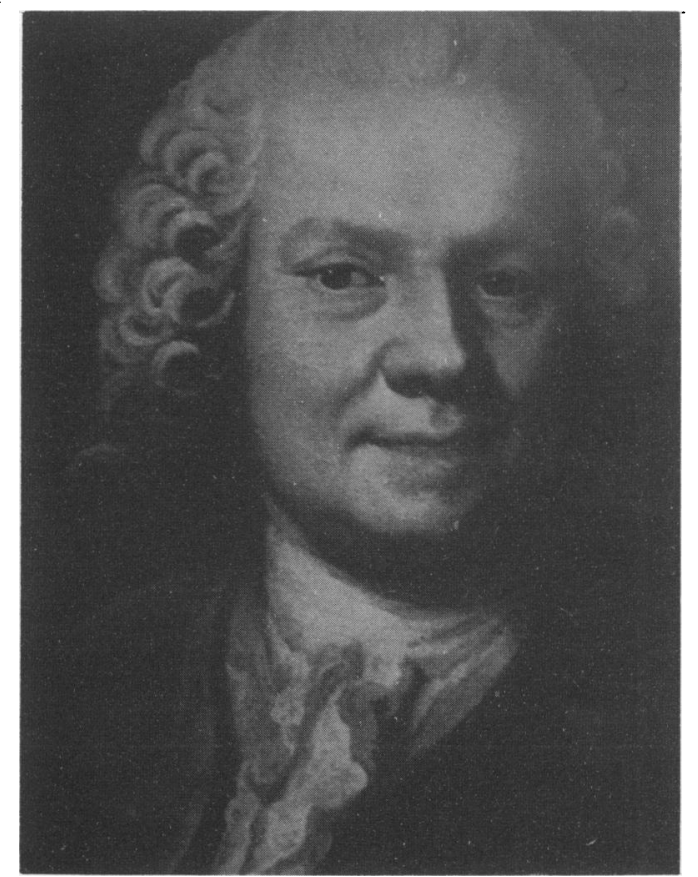

Nils Rosen von Rosenstein, 1706-1773.

'On the aphthae or thrush

This is attended with many bad symptoms, and often endangers the child's life; for besides that children shriek day and night on account of the pain, they are unable to suck, and consequently suffer by both hunger and thirst; if at this time they suck, the nurse's nipples commonly will be excoriated and sore: if the thrush extends to the throat, they have a difficulty of swallowing; if it descends to the stomach, they will have many reachings and hiccough; and if it extends still further down to the bowels, the chyle will be prevented from entering the lacteal vessels, and the blood is carried off by a diarrhoea: if this continues long the child must die for want of nourishment.

The thrush is commonly of a white . . . colour . . . That which appears first upon the lips, gums, tongue, inside of the cheeks, palate, uvula and tonsils is the easiest to cure. It is very difficult when it descends to the fauces, stomach and intestines. It is still more dangerous if it has reached the aspera arteria and the lungs ... The thrush in the mouth is the most common kind, and may generally be prevented by the nurse taking care to keep the child's 
mouth clean, which should be examined every day ....'

Perhaps, though, Rosen's most interesting chapter is that which deals with congenital syphilis.

'On the cure of children born with the venereal disease, or infected with it by nurses

When the parents have a venereal disease, it is very natural that the children they beget will be born with the same. But as the poison (virus venereum) at the time of conception may either be active, vigilant and acute; or inactive, blunt, and dead as it were, its effect on the child will also be different. If the poison is active at that time, the child in the womb will generally lose its life; therefore we find such unhappy mothers often miscarry or are brought to bed with dead children; and in case they be brought into the world still alive, they nevertheless will be found with sores and other evident signs of the venereal disease. Should the poison at such a time be less active, the child may be born with a healthy appearance, but after some time, its body will break out with sores and boils. But when the poison at the time of conception lies dormant, either naturally, or by some remedies which the parents have used, and by which it has not been quite exterpated but only weakened, the child will scarce ever get any venereal disease ... . Such children grow tender and weak, as also their offspring, from generation to generation ... This is the reason that of several children of the same parents, which are in this unhappy condition, some enjoy a perfect health, whilst both the body and the senses of the others are affected....

In the same manner in which a nurse can infect a child, a child also born with the venereal disease may infect its nurse: and here one thing is to be observed, which seldom fails, namely, that the parts which are touched first by the contagion will always suffer first. Therefore when a child is infected by the nurse, it then gets corroding sores in its mouth, but chiefly in the fauces, and the glands of the jaws and in the throat swell and grow hard. If the nurse has gotten the contagion from the child, she will first get the corroding sores on her breasts, and the glands in her armpits grow swelled and indurated ..

The venereal disease is in general curable if it is not suffered to grow too inveterate; for the shorter time it has been in the body, the more easily will it be removed. The cure is more difficult when the bones are already affected.

However, the disease is seldom quite eradicated, because the patient grows tired, and breaks off the cure as soon as the pains have ceased, and the body appears clean. From thence it happens that they get relapses, or grow indisposed for all their life-time . .

I will now advance to the cure itself, and first mention how to relieve a woman who is found to be infected with a venereal disease during the time she is big with child, which consequently must likewise be infected. In such unfortunate circumstances there is no time to lose, but a quick relief is required; for if the cure be deferred till she is delivered, the foetus will in the meantime die, and at least be brought into the world half rotten, or with little life. The mother is during that time subject to miscarry ... Therefore such a patient ought immediately to be well prepared, and with great caution use the mercurial ointments. .

When a child is born with this disease, and is still of a tolerable lively appearance, we have hopes to cure it by the mother's using the mercurial ointment, and the child sucking her during the time. If the mother be too weak, we are obliged to procure the child a nurse who will go through the same cure. It is advisable to make her acquainted with all the circumstances before-hand, in order that the parents may avoid a disagreeable prosecution, as it once happened in France.

But as the mother's or nurse's breast and nipples commonly grow so sore and swelled on suckling such a child, that the milk will not flow, physicians have been obliged to think of another method, which perhaps is the safest; a goat must be well chased and cleared of hair, and rubbed with the mercurial ointment in the same manner as it is done to people; the child must live on her milk during the time till it is cured. Mr D'Aumont, professor in Valence, cured a child in this manner within 35 days ...'

These extracts reveal a remarkably good understanding both of the method of transmission of syphilis and its treatment. The final section is of particular interest because of its use of goats' milk as a therapeutic vehicle and also because it discusses the need for counselling and consent as a defence against medicolegal prosecution-a modern touch!

In 1739 Rosen was elected to the newly formed Royal Academy of Science and was made President in 1746 and in 1772 . In 1734 he was appointed physician to King Fedrik I and for his many services to the royal family was ennobled as Rosen von Rosenstein in 1746 and made a Knight of the Polar Star. He had married Anna Christina Hermansson in 1734 and they had three children, one of whom sadly died after variolation at the age of 4 . Rosen's own health was poor, mainly as a result of rheumatoid arthritis and he resigned his post and retired to Stockholm at the age of 51 in 1757. His health remained poor and he died during a visit to Uppsala in 1773.

1 Rosen von Rosenstein N. The diseases of children and their remedies. Translated by A Sparrman. London: T Cadell, 1776 . 